\title{
Pattern of Mandibular Third Molar Presentation: Ten Years Experience at the University College Hospital Ibadan
}

Adelusi EA* and Okoje VN

Department of Oral and Maxillofacial Surgery, University of Ibadan and University College Hospital, Ibadan, Nigeria

\begin{abstract}
Background: Tooth impaction occurs when a tooth fails to erupt or develop in its proper functional location. The third molar is said to be the most commonly impacted tooth in the oral cavity and accounts for $98 \%$ of all impactions and mandibular third molars are the most frequently impacted.
\end{abstract}

Aim: The purpose of this study was to review 10 years pattern of presentation of mandibular the third molar impaction seen at the University College Hospital in Ibadan.

Material and Methods: A total of 597 impacted third molar teeth were reviewed. The angulations of impacted third molar teeth according to Winter's classifications were recorded as documented in the patient's case note. The cause of extraction such as pericoronitis, caries, other pathology, and orthodontic reason and second molar pathology were noted and recorded for every patient. Distributions of obtained values were compared using the Pearson $X^{2}$ test.

Results: The mean age of the subjects was 27.7 (range: 19-50); in a review of the 597 impacted third molar teeth, the most common angulation of impaction was mesioangular $(320 ; 53.6 \%)$ and pericoronitis $(514 ; 86.2 \%)$ was found to be the most common reason for disimpaction. Among 597 patients ( 244 males, 353 females), pericoronitis was more prevalent in females $(101 ; 30 \%)$.

Conclusion: The pattern of third molar impaction in UCH population was characterized by mesioangular impaction and was more common in females than males. Pericoronitis was the most common symptoms usually associated with level tooth impaction.

Keywords: Review; Pattern; Third molar; Impaction

\section{Introduction}

Tooth impaction is a failure of a tooth to erupt to the normal functional position within the expected time; due to lack of space, or physical barriers [1]. Teeth are said to be impacted when they fail to erupt or develop in their proper functional location [2].

The third molar is said to be the most commonly impacted tooth in the oral cavity and accounts for $98 \%$ of all impactions [2] and mandibular third molars are the most frequently impacted $[3,4]$.

Inadequate space in the mandible, among other factors, is the cause of third molar impaction [5].

There is a substantial variation in the frequency of third molar impaction amongst different populations; and these range between $18 \%$ and $70 \%$ [6-10]. This is attributed to racial variation in facial growth, jaw and tooth size [2].

The impacted teeth can give rise to pathological conditions such as pericoronitis or develop to cystic lesions or other odontogenic pathology $[11,12]$.

Different classification systems have been used to describe impacted third molars, these are Winter's [13] classification system which describe the angle formed between the intersected longitudinal axes of the second and third molars, [13] the Pell and Gregory [14] classification system which assess the level of third molar impaction where the impacted third molars are assessed in relation to the neighboring second molars [14].

Studies have reported different prevalence for impaction of the mandibular third molars and this varies between $16.7 \%$ and $68.6 \%$ [1521]. Most studies available did not find a gender predilection; however, some studies have mentioned a higher incidence of impaction in females when compared to males [15,16,22].
The aim of the present study is to evaluate the pattern of third molar impaction in patients seen in the University College Hospital (UCH) within 10 years in terms of age, gender, angulations of impaction as recorded in the day book and the patients case note, furthermore, cross tabulation between patterns of impaction and gender was evaluated for any significant difference.

\section{Materials and Methods}

This study was undertaken on a group of patients who presented at the exodontias clinic of Oral and Maxillofacial Surgery UCH between January 2007 and December 2016.

A total of 597 patients who had impacted the third molar extracted were included in the study. The data required for each patient were collected retrospectively: Age, Gender, Type of impaction based on angulations and the quadrant where the impacted tooth is located were extracted from their records in the case note and oral and maxillofacial daily record book.

Due to the nature of the study (retrospective study), informed consent could not be obtained from the patients.

Data analysis was completed using SPSS 23.0 software (SPSS Inc.,

*Corresponding author: Emmanuel A Adelusi, BDS (lb), MDS (Ib), FWACS, Department of Oral and Maxillofacial Surgery, University of Ibadan and University College Hospital, Ibadan, Nigeria, Tel: 2348034659807; E-mail: godwithus73@yahoo.com

Received October 18, 2018; Accepted October 22, 2018; Published October 26 2018

Citation: Adelusi EA, Okoje VN (2018) Pattern of Mandibular Third Molar Presentation: Ten Years Experience at the University College Hospital Ibadan Dentistry 8: 516. doi:10.4172/2161-1122.1000516

Copyright: (c) 2018 Adelusi EA, et al. This is an open-access article distributed under the terms of the Creative Commons Attribution License, which permits unrestricted use, distribution, and reproduction in any medium, provided the original author and source are credited. 
Citation: Adelusi EA, Okoje VN (2018) Pattern of Mandibular Third Molar Presentation: Ten Years Experience at the University College Hospital Ibadan. Dentistry 8: 516. doi:10.4172/2161-1122.1000516

Chicago, IL). Statistical tests carried out included Pearson's chi-square and Student's t-test. A P-value less than 0.05 was considered statistically significant. All information gathered was carried out by two examiners to avoid the error of omission.

\section{Results}

The total number of 611 patients who had impacted mandibular third molar extraction done between January 2007 and December 2016 were reviewed but only 597 who had complete information were eventually included in the analysis, 14 patient were not included due to insufficient information and each patient had one mandibular third molar disimpaction done, with a total of 597 third molars that were reviewed and included in the study. The sample consisted of 244 (40.9\%) male and 353 (59.1\%) female (Table 1) with age ranged from 18 to 50 and mean of 27.7 with female having more third molar extraction done more than male and the difference between male and female was statistically significant $\left(X^{2}=16.7\right.$ and P Value $=0.002$ ) (Table 2).

Most patients were recorded in 2011 and the least was recorded in 2014. Six-five were recorded in 2007, 59 in 2008, 53 in 2009, 48 in 2010, 72 in 2011, 49 in 2012, 70 in 2013, 44 in 2014, 66 in 2015, 71 in 2017 with average of 59.7 .

The highest pattern for impacted teeth was mesioangular 320
(53.6\%) impaction and lowest was transverse 2 (0.3\%) (Tables 1-4).

Most third molar extraction that was done in this study was in the third decade where 405 (67.9\%) cases were recorded followed by the fourth decade, a second decade and fifth decade, the difference was statistically significant with $\mathrm{X}^{2}=274.89$ and P Value $=0.0001$ (Table 2).

More third molar extractions were done on the left than the right mandible with a statistically significant difference $\left(\mathrm{X}^{2}=16.61, \mathrm{P}\right.$ Value $=0.00158)$ (Table 3$)$.

There is no different between male and female in the distribution of impacted teeth on the right quadrants $\left(\mathrm{X}^{2}=13.06\right.$, $\mathrm{P}$ Value $\left.=0.005\right)$ while there is a statistically significantly different between male and female in the distribution of impacted teeth on the left quadrant especially the mesioangular impaction with $\left(\mathrm{X}^{2}=24.0413 .06\right.$, $\mathrm{P}$ Value $\left.=0.0001\right)$ (Table 4).

Recurrent pericoronitis $525(85.3 \%)$ was the main cause for extraction followed by caries (Table 5).

\section{Discussion}

The majority of patients in this study were Yoruba tribes between the Age of 18 and 50 years. In this study, we found that the incidence of mandibular third molar impaction was significantly higher in females

\begin{tabular}{|c|c|c|c|c|c|c|}
\hline Gender & Impaction mesioangular & Distoanguler & Horizontal & Vertical & Transverse & Total $\mathbf{x}^{2} \mathbf{P}$ value \\
\hline Male & $111(34.7)$ & $42(52.5)$ & $68(51.5)$ & $22(34.9)$ & $1(50.0)$ & $244(40.9)$ \\
\hline Female & $209(65.3)$ & $38(47.5)$ & $64(48.5)$ & $41(65.1)$ & $1(50.0)$ & $353(59.1)$ \\
\hline Total & $320(100)$ & $80(100)$ & $132(100)$ & $63(100)$ & $2(100)$ & $597(100) 16.72(0.002)$ \\
\hline
\end{tabular}

Table 1: Gender distribution.

\begin{tabular}{|c|c|c|c|c|c|c|}
\hline \multicolumn{7}{|c|}{ Impaction } \\
\hline Age & Mesioangular & Distoangular & Horizontal & Vertical & Transverse & Total $\mathbf{x}^{\mathbf{2}} \mathbf{P}$ value \\
\hline $18-20$ & $15(4.6)$ & $3(3.8)$ & $5(3.8)$ & $0(0.0)$ & $0(0.0)$ & $23(3.9)$ \\
\hline $21-30$ & $231(72.2)$ & $62(77.4)$ & $74(56.1)$ & $36(57.1)$ & $2(100.0)$ & $405(67.8)$ \\
\hline $31-40$ & $67(21.0)$ & $12(15.0)$ & $45(34.1)$ & $24(38.1)$ & $0(0.0)$ & $148(24.7)$ \\
\hline $41-50$ & $7(2.2)$ & $3(3.8)$ & $8(6.0)$ & $3(4.8)$ & $0(0.0)$ & $21(3.5)$ \\
\hline Total & $\mathbf{3 2 0}(\mathbf{1 0 0 . 0 )}$ & $\mathbf{8 0 ( 1 0 0 . 0 )}$ & $\mathbf{1 3 2 ( 1 0 0 . 0 )}$ & $\mathbf{6 3 ( 1 0 0 . 0 )}$ & $\mathbf{2 ( 1 0 0 . 0 )}$ & $\mathbf{5 9 7}(\mathbf{1 0 0 . 0 )}-\mathbf{0 . 0 0 0 1}$ \\
\hline
\end{tabular}

Table 2: Age distribution.

\begin{tabular}{|c|c|c|c|c|c|c|}
\hline \multicolumn{9}{|c|}{ Impaction } \\
\hline Quadrant & Mesioangular & Distoanguler & Horizontal & Vertical & Transverse & Total $\mathbf{x}^{\mathbf{2}} \mathbf{P}$ value \\
\hline Right & $112(35.0)$ & $32(40.0)$ & $61(46.2)$ & $22(34.9)$ & $0(0.0)$ & $227(38.0)$ \\
\hline Left & $208(65.0)$ & $48(60.0)$ & $71(53.8)$ & $41(65.1)$ & $2(100.0)$ & $370(62.0)$ \\
\hline Total & $\mathbf{3 2 0 ( 1 0 0 )}$ & $\mathbf{8 0 ( 1 0 0 )}$ & $\mathbf{1 3 2 ( 1 0 0 )}$ & $\mathbf{6 3 ( 1 0 0 )}$ & $\mathbf{2 ( 1 0 0 )}$ & $\begin{array}{c}\mathbf{5 9 7}(\mathbf{1 0 0}) \mathbf{1 6 . 6 1} \\
\mathbf{0 . 0 0 1 5 8}\end{array}$ \\
\hline
\end{tabular}

Table 3: The affected quadrant.

\begin{tabular}{|c|c|c|c|c|c|c|c|c|c|}
\hline \multicolumn{10}{|c|}{ Impaction } \\
\hline Quadrant & Gender & Mesioangular & Distoangular & Horizontal & Vertical & Transverse & Total & $x^{2}$ & $P$ value \\
\hline \multirow{3}{*}{ Right } & Male & $59(52.7)$ & $19(59.4)$ & $31(50.8)$ & $3(13.6)$ & $0(0.0)$ & $112(49.3)$ & & \\
\hline & Female & $53(47.3)$ & $13(40.6)$ & $30(49.2)$ & $19(86.4)$ & $0(0.0)$ & $115(50.7)$ & & \\
\hline & Total & $112(100.0)$ & $32(100.0)$ & $61(100.0)$ & $22(100.0)$ & $0(0.0)$ & $227(100.0)$ & 13.06 & 0.005 \\
\hline \multirow{3}{*}{ Left } & Male & $52(25.0)$ & $23(47.9)$ & $37(52.1)$ & $19(46.3)$ & $1(50.0)$ & $132(35.7)$ & & \\
\hline & Female & $156(75.0)$ & $25(52.1)$ & $34(47.9)$ & $22(53.7)$ & $1(50.0)$ & $238(64.3)$ & & \\
\hline & Total & $208(100.0)$ & $48(100.0)$ & $71(100.0)$ & $41(100.0)$ & $2(100.0)$ & $370(100.0)$ & 24.04 & 0.0001 \\
\hline \multirow{3}{*}{ Total } & Male & $111(34.7)$ & $42(52.5)$ & $68(51.5)$ & $22(34.9)$ & $1(50.0)$ & $244(40.9)$ & & \\
\hline & Female & $209(65.3)$ & $38(47.5)$ & $64(48.5)$ & $41(65.1)$ & $1(50.0)$ & $353(59.1)$ & & \\
\hline & Total & $320(100.0)$ & $80(100.0)$ & $132(100.0)$ & $63(100.0)$ & $2(100.0)$ & $597(100.0)$ & 16.72 & 0.002 \\
\hline
\end{tabular}

Table 4: Quadrant, gender, and type of impaction tabulation. 
Citation: Adelusi EA, Okoje VN (2018) Pattern of Mandibular Third Molar Presentation: Ten Years Experience at the University College Hospital Ibadan. Dentistry 8: 516. doi:10.4172/2161-1122.1000516

Page 3 of 4

\begin{tabular}{|c|c|c|c|c|c|c|}
\hline \multicolumn{7}{|c|}{ Cause } \\
\hline Gender & Pericoronitis & Caries & Other pathology & Orthodontic reason & 2nd Molar Pathology & Total \\
\hline Male & $201(39.5)$ & $19(47.5)$ & $9(52.9)$ & $8(53.3)$ & $7(43.8)$ & $244(40.9)$ \\
\hline Female & $308(60.5)$ & $21(52.5)$ & $8(47.1)$ & $7(46.7)$ & $9(56.2)$ & $353(59.1)$ \\
\hline Total & $\mathbf{5 0 9 ( 1 0 0 . 0 )}$ & $\mathbf{4 0 ( 1 0 0 . 0 )}$ & $\mathbf{1 7 ( 1 0 0 . 0 )}$ & $\mathbf{1 5 ( 1 0 0 . 0 )}$ & $\mathbf{1 6 ( 1 0 0 . 0 )}$ & $\mathbf{5 9 7}(\mathbf{1 0 0 . 0 )}$ \\
\hline
\end{tabular}

Table 5: Associated pathology.

when compared with males. This finding is in agreement with the findings in the literature $[8,9,15,20]$. The higher incidence in women has been attributed to the fact that the physical growth in women usually stops earlier than men leading to a smaller jaw size [8,9]. Also, the initiation of third molar eruption in women is said to occur after the growth of the jaw is completed unlike in men whose jaw growth continues during the third molar eruption and thus provides more space for the tooth [9].

Some studies however did not find gender differences in the pattern of third molar impaction $[7,18,19]$.

More third molar extractions were done on the left than the right mandible with a statistically significant difference. There is no difference between male and female in the distribution of impacted teeth on the right quadrants while there is a statistically significantly different between males and females in the distribution of impacted teeth on the left quadrant especially the mesioangular disimpaction.

In the present study, the most common type of angulation of impacted mandibular third molar was mesioangular, followed by horizontal, distoangular, vertical and transverse being the least. The findings are similar to those of Eshghpour et al. [8]. It is also similar to that of Hashemipour et al [15] who found that mesioangular impaction was the most prevalent type of impaction in the mandibular third molars of African American, Singaporean, American, Arabian, and Iranian populations, respectively.

However, some studies reported that the most common angulation of third molar impaction was the vertical position. [20-23].

Most third molar extraction that was done in this study was in the third decade where 405 (67.9\%) cases were recorded followed by the fourth decade, a second decade and fifth decade. This is in agreement with the findings in the literature [24,25].

In this study, we found that pericoronitis is the main reason for impacted mandibular third molar disimpaction. The findings are similar to those of Jamileh and Pedlar [26] et al. and Khawaja [27]. There was a tendency in female patients for pericoronitis, but other symptoms showed no gender predominance. This finding is similar to those of Bataineh et al. [21] and Yamalık and Bozkaya et al. [28]. However, Almendros-Marqués et al. [22] and Akarslan and Kocabay et al. [29] found no gender predominance for all complaints and pathologies. While Yilmaz et al. [23] reported male predominance.

Prajapati, et al. [30] in their study, recorded caries (especially of the adjacent tooth) and its sequelae as the major reason $(63.2 \%)$ for the mandibular third molar extraction, followed by recurrent pericoronitis (26.3\%) and periodontitis (9.2\%) [25]. Allen et al. [31] reported the incidence of $42 \%$ of the distal second molar caries associated with partially or completely impacted mandibular third molars [31].

\section{Conclusion}

Impacted teeth are commoner in females than males and in the left side than the right. Mesioangular impaction is the most occurred of all impaction and also commoner on the left side than on the right. This is true for all the years put together and also from an individual year and more in the third decade of life.

\section{Reference}

1. Agarwal KN, Gupta R, Faridi MM, Kalra N (2004) Permanent dentition in Delhi boys of age 5-14 years. Indian Pediatr 41: 1031-1035.

2. Padhye MN, Dabir AV, Girotra CS, Pandhi VH (2013) Pattern of mandibular third molar impaction in the Indian population: a retrospective clinico-radiographic survey. Oral Surg Oral Med Oral Pathol Oral Radiol 116: e161-e166.

3. Dimitroulis G (1997) A synopsis of minor oral surgery. 4th ed. Oxford, UK: Butterworth-Heinemann Publishing 48-57.

4. Eshghpour M, Rezaei NM, NejatA(2013) Effect of menstrual cycle on frequency of alveolar osteitis in women undergoing surgical removal of mandibular third molar: A single-blind randomized clinical trial. J Oral Maxillofac Surg 71: 1484 1489.

5. Al-Anqudi SM, Salim Al-Sudairy, Ahmed Al-Hosni, Abdullah Al-Maniri (2014) Prevalence and pattern of third molar impaction. Univ Med J 14: e388-e392.

6. Kumar Pillai A, Thomas S, Paul G, Singh SK, Moghe S (2014) Incidence of impacted third molars: a radiographic study in People's hospital, Bhopal, India. J Oral Biol Craniofac Res 4: 76-81.

7. Hattab FN, Fahmy MS, Rawashedeh MA (1995) Impaction status of third molars in Jordanian students. Oral Surg Oral Med Oral Pathol Radiol Endod 79: 24-29.

8. Eshghpour M, Nezadi A, Moradi A, Shamsabadi RM, Rezaei NM, et al. (2014) Pattern of mandibular third molar impaction: a crosssectional study in northeast of Iran. Niger J Clin Prac 17: 673-677.

9. Quek SL, Tay CK, Tay KH, Toh SL, Lim KC (2003) Pattern of third mola impaction in a Singapore Chinese population: a retrospective radiographic survey. Int J Oral Maxillafac Surg 32: 548-552.

10. Gupta S, Bhowate RR, Nigam N, Saxena S (2011) Evaluation of impacted mandibular third molar by panoramic radiography. ISNR Dent 2011: 1-8.

11. Ma'aita JK (2000) Impacted third molars and associated pathology in Jordanian patients. Saudi Dent J 12: 16-19.

12. Rajkumar K, Ramen S, Chowdhury R, Chattopadhyay PK (2009) Mandibular third molars as a risk factor for angle fracture: a retrospective study. J Maxillofac Oral Surg 8: 237-240.

13. Winter GB (1926) The principles of exodontia as applied to the impacted third molars: A complete treatise on the operative technic with clinical diagnoses and radiographic interpretations. St Louis, Missouri: American Medical Book Co.

14. Pell GJ, Gregory GT (1942) Report on a ten year study of a tooth division technique for the removal of impacted teeth. Am J Orthod Oral Surg 28: 660666.

15. Hashemipour MA, Tahmasbi-Arashlow M, Fahimi-Hanzaei F (2013) Incidence of impacted mandibular and maxillary third molars: A radiographic study in a Southeast Iran population. Med Oral Patol Oral Cir Bucal 18: e140-e145.

16. Scherstén E, Lysell L, Rohlin M (1989) Prevalence of impacted third molars in dental students. Swed Dent J 13: 7-13.

17. Fanning EA, Moorrees CF (1969) A comparison of permanent mandibula molar formation in Australian aborigines and Caucasoids. Arch Oral Biol 14: 999-1006.

18. Brown LH, Berkman S, Cohen D, Kaplan AL, Rosenberg M (1982) A radiological study of the frequency and distribution of impacted teeth. J Dent Assoc S Afr 37: 627-630.

19. Haidar Z, Shalhoub SY (1986). The incidence of impacted wisdom teeth in a Saudi community. Int J Oral Maxillofac Surg 15: 569-571. 
Citation: Adelusi EA, Okoje VN (2018) Pattern of Mandibular Third Molar Presentation: Ten Years Experience at the University College Hospital Ibadan. Dentistry 8: 516. doi:10.4172/2161-1122.1000516

20. Hugoson A, Kugelberg CF (1988) The prevalence of third molars in a Swedish population. An epidemiological study. Community Dent Health 5: 121-138.

21. Bataineh AB, Albashaireh ZS, Hazza'a AM (2002) The surgical removal of mandibular third molars: a study in decision making. Quintessence Int 33: 613-617.

22. Almendros-Marqués N, Berini-Aytés L, Gay-Escoda C (2006) Influence of lower third molar position on the incidence of preoperative complications. Oral Surg Oral Med Oral Pathol Oral Radiol 102: 725-732.

23. Yilmaz S, Adisen MZ, Misirlioglu M, Yorubulut S (2015) Assessment of third molar impaction pattern and associated clinical symptoms in a Central Anatolian Turkish Population. Med Princ Pract 25: 169-175.

24. Hassan H (2010) Pattern of third molar impaction in a Saudi population. Dove Press J Clin Cosmet Investig Dent 2: 109-113.

25. Krausz AA, Machtei EE, Peled M (2005) Effects of lower third molar extraction on attachment level and alveolar bone height of the adjacent second molar. In J Oral Maxillofac Surg 34: 756-760.
26. Jamileh Y, Pedlar J (2003) Effect of clinical guidelines on practice for extraction of lower third molars: Study of referrals in 1997 and 2000. Br J Oral Maxillofac Surg 41: 371-375.

27. Khawaja AN (2006) Third molar impaction. A review. Pak Oral Dent J 15: 97-101

28. Yamalık K, Bozkaya S (2007) The predictivity of mandibular third molar position as a risk indicator for pericoronitis. Clin Oral Investig 12: 9-14.

29. Akarslan ZZ, Kocabay C (2009) Assessment of the associated symptoms, pathologies, positions and angulations of bilateral occurring mandibular third molars: is there any similarity? Oral Surg Oral Med Oral Pathol Oral Radiol 108: e26-e32.

30. Prajapati VK, Mitra R, Vinayak KM (2017) Pattern of mandibular third molar impaction and its association to caries in mandibular second molar: A clinical variant. Dent Res J 14: 137-142.

31. Allen RT, Witherow H, Collyer J, Roper HR, Nazir MA, et al. (2009) The mesioangular third molar-to extract or not to extract? Analysis of 776 consecutive third molars. Br Dent J 206: e23. 